\title{
CIC resource sharing project
}

\author{
By Carolyn A. Snyder \\ Associate Dean for Public Services \\ Indiana University
}

and Beth J. Shapiro

Deputy Director

Michigan State University

\section{A successful resource sharing and interlibrary loan program sponsored by the Committee on Institutional Cooperation.}

$\mathbf{T}$ he CIC Resource Sharing Project described below is an example of a resource sharing/interlibrary loan program that 1) has been accomplished with the existing resources of each of the institutions 2) has been accomplished between institutions utilizing both OCLC and RLIN and 3) has the strong support of both administrators and librarians within the institutions. A number of aspects of the program were evaluated. Overall, the trial period was judged a success leading to implementation on a continuing basis.

The Committee on Institutional Cooperation was established in 1958 and has eleven member institutions, the "Big Ten" Universities and the University of Chicago (Chicago, Illinois, Indiana, Iowa, Michigan, Michigan State, Minnesota, Northwestern, Ohio State, Purdue and Wisconsin). The directors of the libraries of these institutions meet regularly to consider issues of shared interest and to plan for implementation of joint programs such as a cooperative microfilming project, a reciprocal borrowing program for faculty, and telecommunications/networking developments.

The Committee on Institutional Cooperation Resource Sharing Project began in 1987 as an experimental program at the initiative of public services and collection development librarians. All eleven institutions agreed to participate including the eligible health sciences libraries on six of the campuses.
The Project's first year was evaluated in August 1988, with the evaluation period covering July 1987 through June $1988 .{ }^{1}$ Initially the program of interlibrary lending included the free loaning of monographs and free photocopies (with some limitations) among CIC libraries. The CIC Resource Sharing Task Force ${ }^{2}$ had considered a number of options but decided on free loans and photocopies which could be accomplished without additional resources. While the intention was to waive interlibrary loan fees for all items lent, theses and dissertations presented difficulties for some members. Nevertheless, in the spirit of furthering cooperation, the institutions resolved these issues. By the end of 1988, all CIC institutions had begun loaning dissertations to one another.

Successful implementation involved careful planning by the public services directors and interlibrary loan librarians. Planning issues included record keeping, identification of incoming interlibrary loan requests as part of the program, the sharing of interlibrary loan borrowing and lending

${ }^{1}$ Shapiro, Beth J. CIC Resource Sharing Project Evaluation. Unpublished, March 1989.

${ }^{2}$ The current membership is Anne Beaubien, Michigan; Carl Deal, Illinois; Beth Shapiro, Michigan State; Kathryn Deiss, Northwestern; Carolyn Snyder, Chair, Indiana. 
information for each library, and an evaluation process. It was agreed that lending and borrowing statistics would be complied and distributed for each month including the number of photocopy exposures (recording the number of photocopy exposures was discontinued in January 1989 at request of interlibrary loan librarians).

To share information, resolve problems and discuss areas in which resource sharing should be enhanced, the CIC Resource Sharing Task Force and the CIC Interlibrary Loan Librarians met regularly during the ALA Conferences. At the recommendation of these groups and with the approval of the directors, the program was expanded. Five of the eleven CIC libraries are lending materials within CIC that they would not have lent prior to this program, including dissertations/theses, bound serials, fragile material, and audiovisual materials. In early 1989, most CIC libraries agreed in principle to consider borrowing requests from CIC libraries for any materials in their collections, regardless of format, and to make them available at no cost if possible. Eight of the eleven CIC libraries began on August 7, 1989, sending all periodical articles by telefax to reduce turnaround time for interlibrary loan photocopies. Planning currently is underway to use CICnet, a high-speed data telecommunications network to transmit articles by telefax thereby reducing telecommunications charges.

Using the statistics gathered since the beginning of the program and a questionnaire distributed to each library, the program was evaluated for the period from July 1987 through June 1988. The evaluation did not include comparisons of lending volume and patterns of pre- and post-program implementation, as adequate data were not available for the pre-program period.

\section{Lending and borrowing patterns}

Membership of the CIC libraries in OCLC and RLIN has been an important factor in use patterns. Of the eleven participating institutions, seven are primary users of the OCLC Interlibrary Loan Subsystem (Chicago, Illinois, Indiana, Michigan State, Ohio State, Purdue, and Wisconsin), three are primary users of the RLIN Interlibrary Loan Subsystem (Iowa, Michigan, and Northwestern), and one uses both systems heavily (Minnesota). For evaluation purposes, Minnesota was included as an RLIN user. As might be expected, utility use significantly influenced borrowing patterns.

Of the total borrowing activity of CIC libraries (from CIC and non-CIC sources) during FY 88, $18 \%$ of the activity consisted of borrowing from each other. While only $5.4 \%$ of all lending activity was to other CIC libraries.

When this project was initiated, several directors were interested in information about which libraries were net lenders/borrowers. Although this information was provided to directors as part of the evaluation, it did not have a significant impact on the decision to continue the program.

\section{Fill rate and turnaround time}

Fill rate and turnaround time information was

BORROWING PATTERNS BY UTILITY

\section{RLIN}

Iowa

Michigan

Minnesota

Northwestern
$83 \%$ from other RLIN users

$48 \%$ from other RLIN users

$58 \%$ from other RLIN users

$80 \%$ from other RLIN users

\section{$O C L C$}

\section{Chicago \\ Illinois \\ Indiana \\ Michigan State \\ Ohio State \\ Purdue \\ Wisconsin}

$90 \%$ from other OCLC users
$85 \%$ from other OCLC users
$80 \%$ from other OCLC users
$85 \%$ from other OCLC users
$77 \%$ from other OCLC users
$91 \%$ from other OCLC users
$64 \%$ from other OCLC users

NOTE: Michigan's figure is low because it borrows heavily from Michigan State as part of an arrangement in existence prior to the start of the CIC project. Minnesota's figure is low because it uses OCLC extensively. Wisconsin's figure is low because it has maintained a long-standing relationship with Minnesota. 
compiled. When this project was initiated, some of the collection development and public services administrators wanted to implement a priority system for CIC requests which they believed would improve both turnaround time and fill rates. The interlibrary loan librarians objected, indicating that the effect of establishing a separate routine for CIC would be an overall deterioration of service. Therefore, the priority was placed locally on improving service overall. Clearly, that has been more successful in some institutions than in others, and it is an area requiring further discussion and attention.

The interlibrary loan librarians were asked to provide their perceptions of average turnaround time for receipt of requests as data on turnaround time was not collected. Nine indicated the range was from 1-2 weeks, while two said 2-3 weeks. Seven indicated that turnaround time was inadequate. All participants agree that delivery alternatives to the U.S. mail needed to be explored. The most obvious suggestions were the use of United Parcel Service (UPS) and telefacsimile equipment. As noted previously, a telefax experiment was begun recently. The delivery system within the state of Illinois was specifically cited as a model to be explored.

\section{Workflow}

Eight institutions responded that the project resulted in work-flow changes-some positive and some negative. The positive changes included streamlining some procedures and reduced billing and invoicing operations. Several have had to keep statistics not required before.

\section{Financial impact}

Many libraries indicated that they were spending less money to borrow material, although few could provide specific figures. One library indicated a savings of only $\$ 200-\$ 400$ while two reported savings of $\$ 13,000$ and $\$ 14,000$. It was difficult to determine if interlibrary lending revenues had declined because each institution's overall lending activity had increased. Three libraries indicated no decline, four indicated a slight decline, and four indicated declines of $\$ 4,000$ $\$ 12,000$.

\section{Conclusion}

In conclusion, this project was judged to be worthwhile both in terms of improving resource sharing and in terms of communication among counterpart groups (interlibrary loan, collection development, public services) in CIC institutions by ILL librarians, public services, collection development librarians and directors. A number of enhancements have been suggested, including a faster delivery/turnaround time, participation by all libraries on a particular campus, and the use of technological developments such as the possible use of CICNet instead of regular telephone voice lines for telefacsimile transmission. As the project proceeds, ways to improve performance and speed delivery will continue to be discussed and implemented.

\section{Letters}

\section{Physics journals}

\section{To the Editor:}

I would like to point out an apparent error in Katharine Clark and William Kinyon's article, "The Interdisciplinary Use of Physics Journals," February 1989, pp. 145-50. In Table 3 (coverage of 36 physics journals by 8 major indexes), Chemical Abstracts is shown as not covering a number of titles. Searching the CAS Online file's source field (/so) with journal abbreviations and limiting retrieval to publications dated 1983-1985 gives the following: Classical \& Quantum Gravity (57 articles), Nuevo Cimento (1,493 articles), Zeitschrift für Physik-B (407 articles).

Please also note that strictly speaking CAS does not cover English translations of foreign-language journals. This, because as a matter of policy they abstract the foreign-language publication. Your readers will be interested in the following figures (for 1983-1985): Pisma Zh Eksp Teor Fiz (JETP Letters) 933 articles, Yad Fiz (Soviet J Nucl Phys) (1,402 letters), Fiz Elem Chastits Yad (Sov J Part Nucl) (82 articles), and Zh Eksp Teor Fiz (Sov Phys-JETP) (949 articles).

Those results argue very strongly for searching CAS Online for "physics" questions. At Caltech, CAS Online is searched routinely for virtually all science and engineering questions (except for pure mathematics), in conjunction with searches in other databases (such as Inspec, Biosis, Medline, or the SCI)._Dana L. Roth, Head, Science \& Engineering Libraries, California Institute of Technology, Pasadena. 